\title{
REMINERALIZATION PRODUCTS EFFECT ON HUMAN ENAMEL IN VITRO STUDY
}

\author{
LAURA SILAGHI-DUMITRESCUa, ANA MARIA MIHĂILESCUc, \\ ALEXANDRINA MUNTEAN ${ }^{b^{*}}$, CODRUTA SAROS ${ }^{\mathrm{a}}$, \\ DOINA PRODAN ${ }^{\mathrm{a}}$, MEDA ROMANA SIMU ${ }^{\mathrm{b}}$, MARIOARA MOLDOVAN ${ }^{\mathrm{a}}$, \\ ANDREA KUI ${ }^{d}$, MIHAELA PASTRAV ${ }^{b}$
}

\begin{abstract}
The aim of this in vitro study was to assess the remineralization process of human enamel, using two commercial pastes (containing calcium, phosphates, hydroxyl-apatite and sodium fluoride) and an experimental gel (obtained from fruit extract). 40 caries free extracted human teeth were divided into 4 groups: 3 study groups $(n=12)$, and 1 control group $(n=4)$. For the study groups, the remineralization agent differed: GC Tooth Mousse, Recaldent, Remin Pro (Voco) and an experimental gel made by "Raluca Ripan" Chemistry Institute (Cluj Napoca, Romania). ATR-FTIR (Jasco-610, Japan) was employed to verify the protective effect of the remineralizing products on enamel. UV-Vis spectra were used to determine mineral loss and gain during demineralizationremineralization process. No significant statistic difference emerged between specimens in study groups and the specimens in control group. Under the limitations of the in vitro study, the application of the tested product proved to be effective on enamel remineralization.
\end{abstract}

Keywords: remineralization, enamel, mineral deficiency

a Babes Bolyai University, "Raluca Ripan" Institute for Research in Chemistry 30 Fântânele street, RO-400294

b Iuliu Haţieganu University of Medicine and Pharmacy, Paediatric Dentistry Department, 31 A. lancu street, RO-400083

c Iuliu Haţieganu University of Medicine and Pharmacy, Department of Oral Rehabilitation, Health and Management, $15 \mathrm{~V}$. Babes street, RO-400012

d Iuliu Haţieganu University of Medicine and Pharmacy, Department of Dental Prosthetics, 31 Clinicilor street, RO-400006.

*Corresponding author: andaorto@yahoo.com 


\section{INTRODUCTION}

Dental enamel is composed of $96 \%$ inorganic material and $4 \%$ organic material and water. The inorganic component, morphologically, arranged in the form of densely packed rods or prisms consist on millions of hydroxyapatite crystals. Enamel's organic matrix contains $35-40 \%$ insoluble fractions - like aminoacids, organized in polypeptides chains. The characteristics of these proteins resemble in some directions with collagen and keratin. The rest of 60$65 \%$ of the organic martix consists on soluble proteins (15\%), other peptides (25\%), citric acid $(20 \%)$ and glycoproteins (5\%) [1].

The enamel's water (about $97 \%$ of it) is attached to the protein molecules; extremely low quantity of water can be found inside the interprismatic spaces of hydroxyl-apatite's, especially near the enamel-dentine junction [2].

The biomineralization of enamel is a complex process through which the extracellular matrix proteins (like amelogenin) mediate the production of hydroxyapatite crystals (starting from calcium and phosphates). This process of biomineralization induced and controlled by intracellular and extracellular matrix, allowed the inorganic ions to attach to a biological structure. The biological structure (made from anionic macromolecules represented by phospholipids, glycoproteins and phosphoproteins) acts like a frame of extracellular and intracellular matrix on which inorganic elements will deposit $[3,4]$.

A prolonged exposure of the dental enamel to acids derived from juices (citric acid, phosphoric acid, carbonic acid) can lead to dental erosion and demineralization of the hard tissues. On the other hand, according to the literature, the biomineralization of dental enamel with different materials - like bio-active glasses, collagen, different phosphate and calcium resin-based cements or calcium silicate cements - may be used to achieve mineral gain of hard dental tissues $[5,6,7]$

The current study was designed to compare the remineralization process of human enamel, using two commercial pastes (containing calcium, phosphates, hydroxyl-apatite and sodium fluoride) and an experimental gel (obtained from fruit extract).

\section{RESULTS AND DISCUSSION}

For the human teeth from control group (stored in artificial saliva AS), evaluated at 7 and 20 days, no modification regarding dental enamel structure emerge. (Fig.1) 


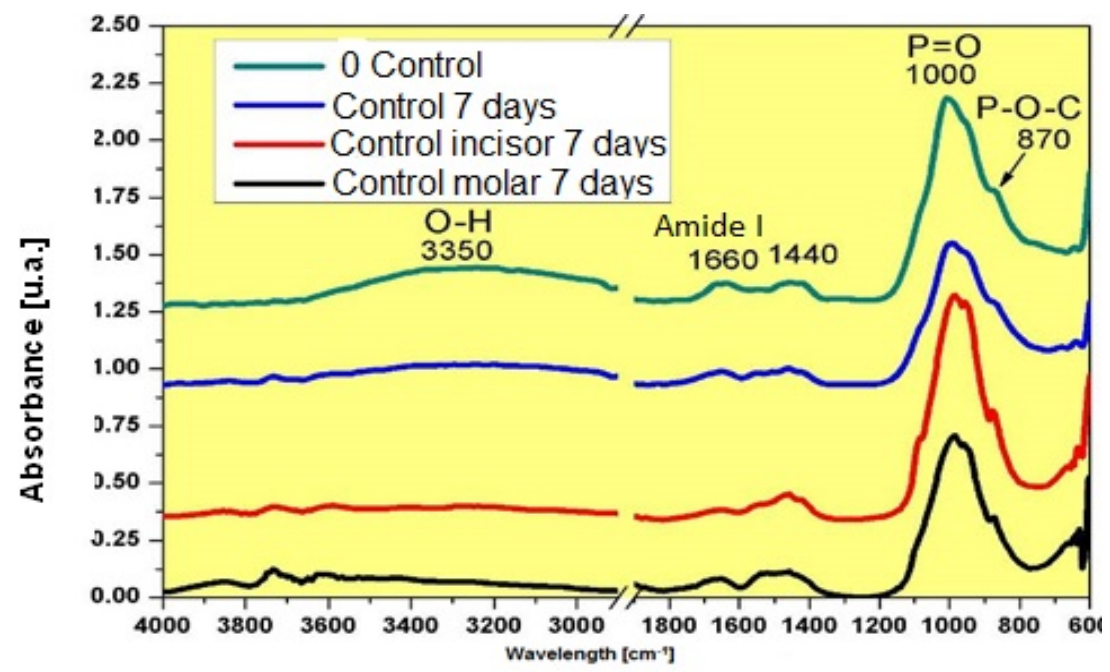

Figure 1. The absorption spectra in ATR-FTIR for human teeth immersed in AS for 7 days

GC Tooth Mousse $\odot$ (Recaldent) was the agent to remineralize the teeth included in the first study group. Teeth demineralized with citric acid did not reveal statistically significant differences after demineralization-remineralization protocol. (Fig. 2-a)

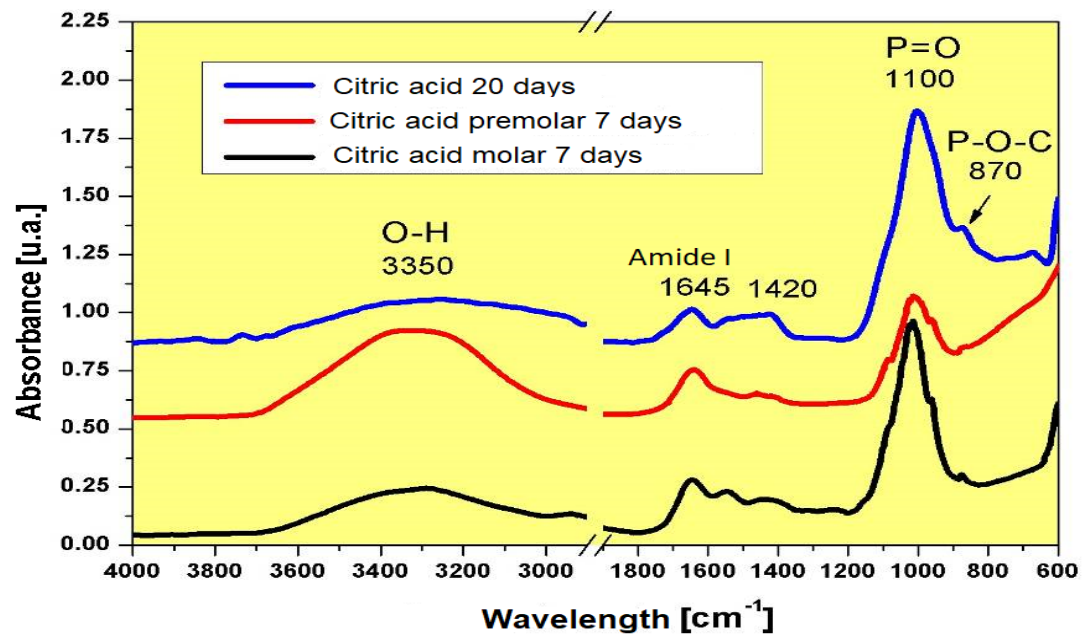

Figure 2-a. The absorption ATR-FTIR spectra for human teeth in first study group (after demineralization and remineralization with GC Tooth Mousse $\odot$ (Recaldent) 
L. SILAGHI-DUMITRESCU, A. MUNTEAN, A.M. MIHĂILESCU, C. SAROSI, D. PRODAN, M.R. SIMU, M. MOLDOVAN, A. KUI, M. PASTRAV

No significant statistic difference emerged between specimens in study group 1 demineralized with Coca Cola solution and remineralized with GC Tooth Mousse $\odot$ (Recaldent) and the specimens in control group. (Fig. 2-b)

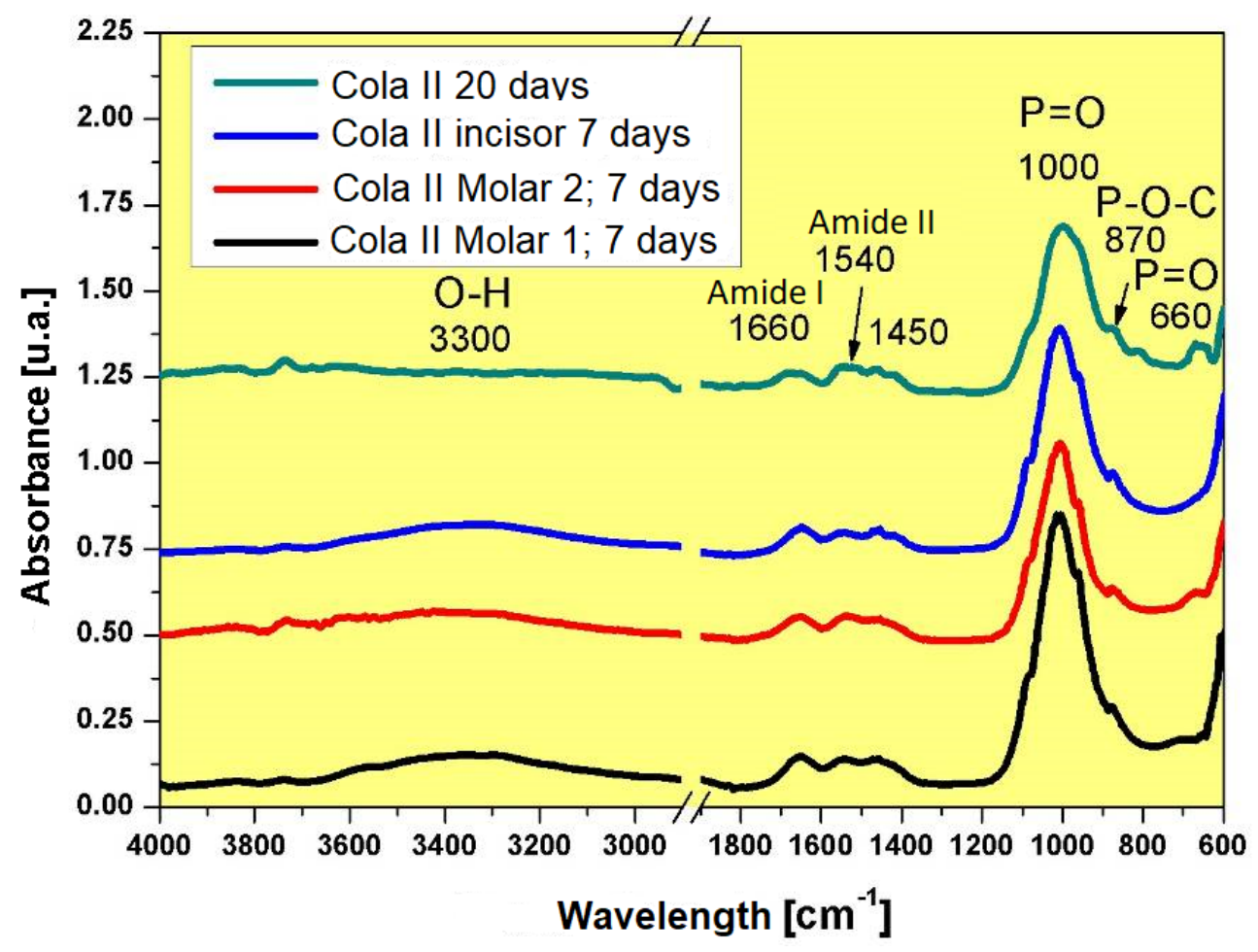

Figure 2-b. The absorption spectra in ATR-FTIR of human teeth de-mineralized in Coca Cola solution and remineralized with commercial tooth paste GC Tooth Mousse $\odot$ (Recaldent)

For the study group 2, for the remineralization processes another commercial available paste with hydroxyapatite and sodium fluoride has been used (Remin Pro@ - Voco). The differences were not statistically significant when compared with the teeth in control group. (Fig. 3a, 3b) 


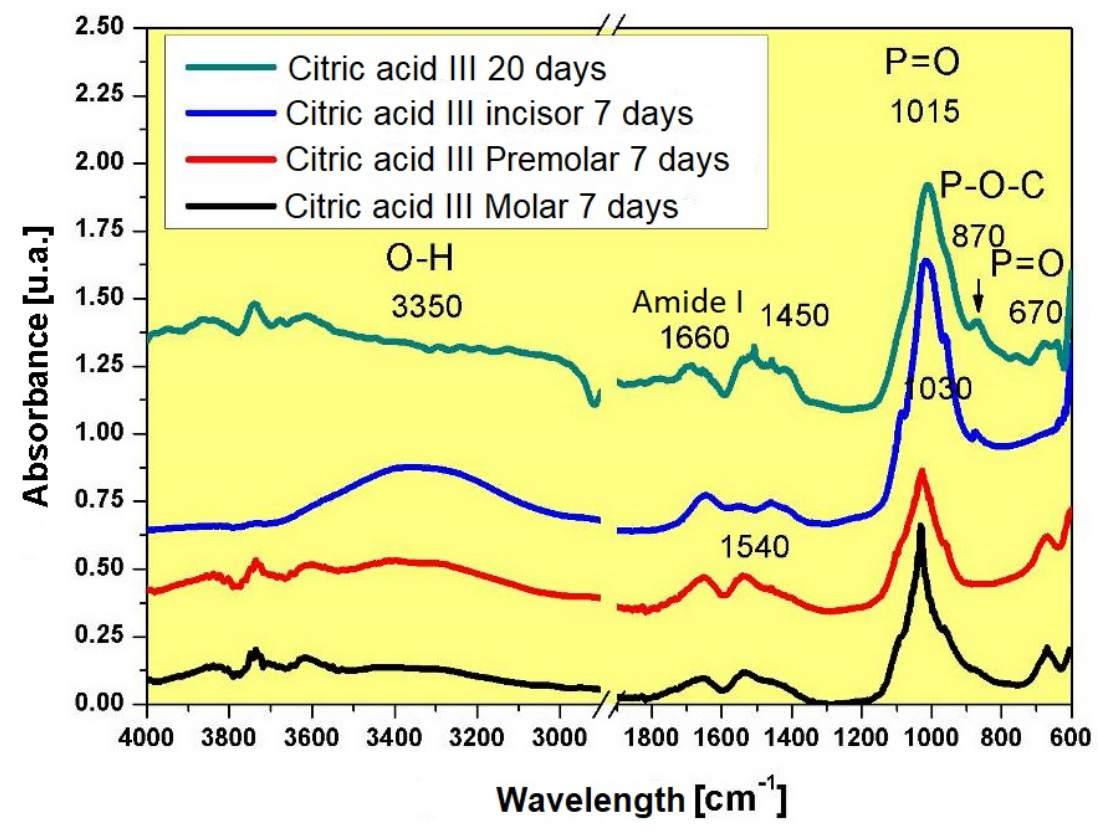

Figure 3-a. Absorption spectra in ATR-FTIR for human teeth demineralized with citric acid solution and remineralized with Remin Pro@ (Voco)

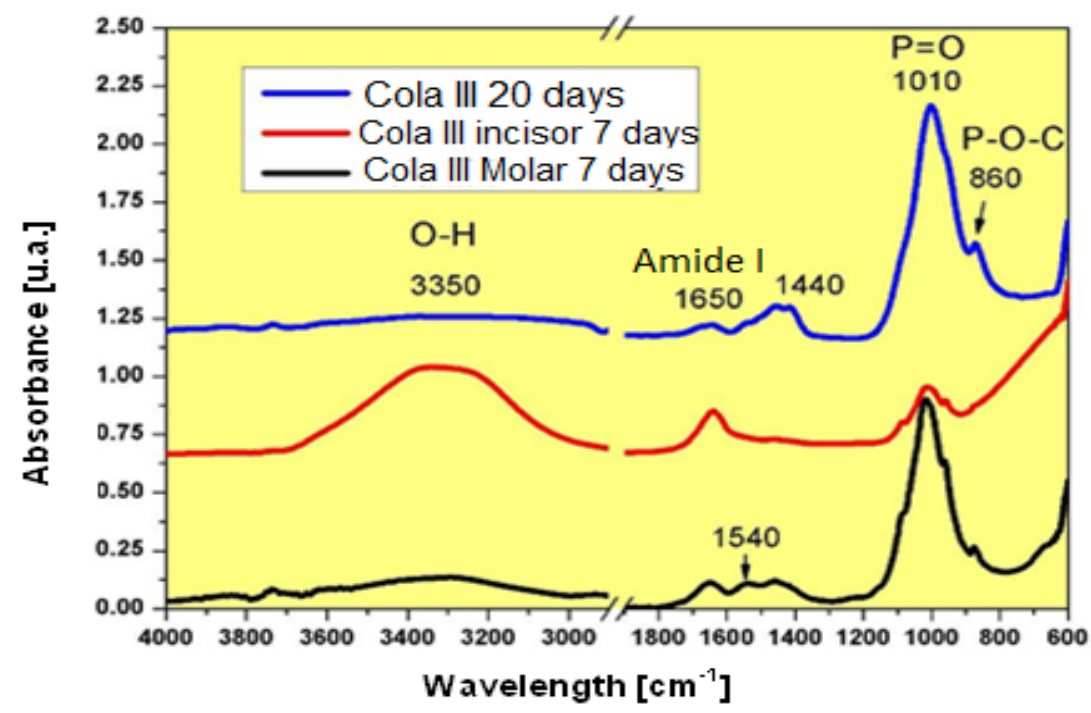

Figure 3-b. The absorption spectra in ATR-FTIR of human teeth demineralized in Coca Cola solution and remineralized with Remin Pro - Voco paste 
For the study group 3, teeth were demineralized using the same protocol other than the remineralization process was performed with an experimental gel made by the "Raluca Ripan" Chemistry Institute, Cluj Napoca (Fig. 4-a and 4-b). The experimental gel (G29), incorporate: coloidal silica/ hydroxyapatite/ hydroxyapatite with zinc oxide $=1: 2: 3$; lyophilized concentrate from pineapple and quince; vegetal pectin $=4-6 \mathrm{~g}$; at $\mathrm{pH}=7.5-8$.

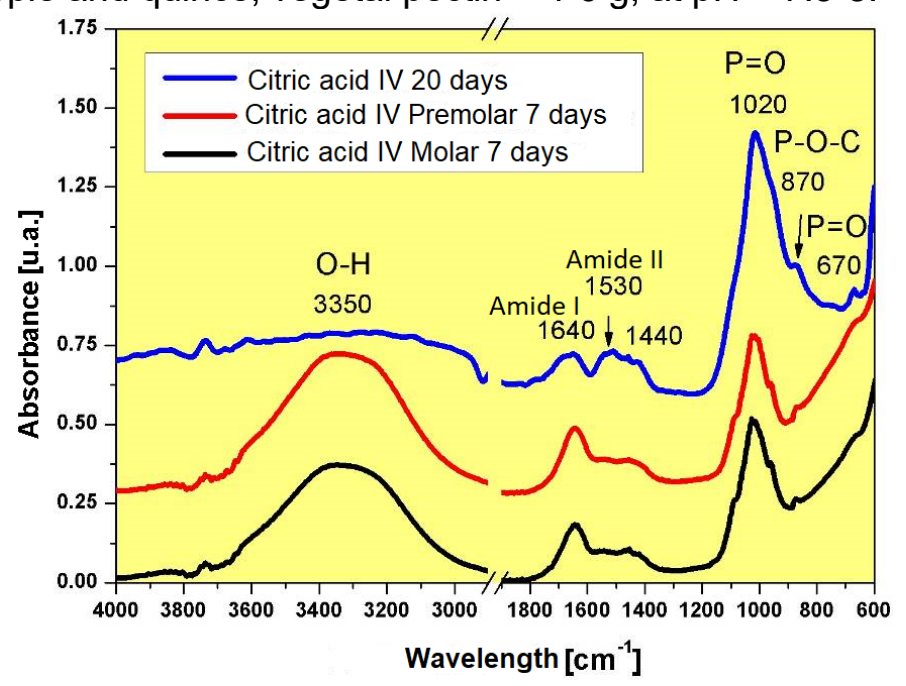

Figure 4-a. The absorption spectra in ATR-FTIR of human teeth demineralized in citric acid and remineralized with experimental gel G29

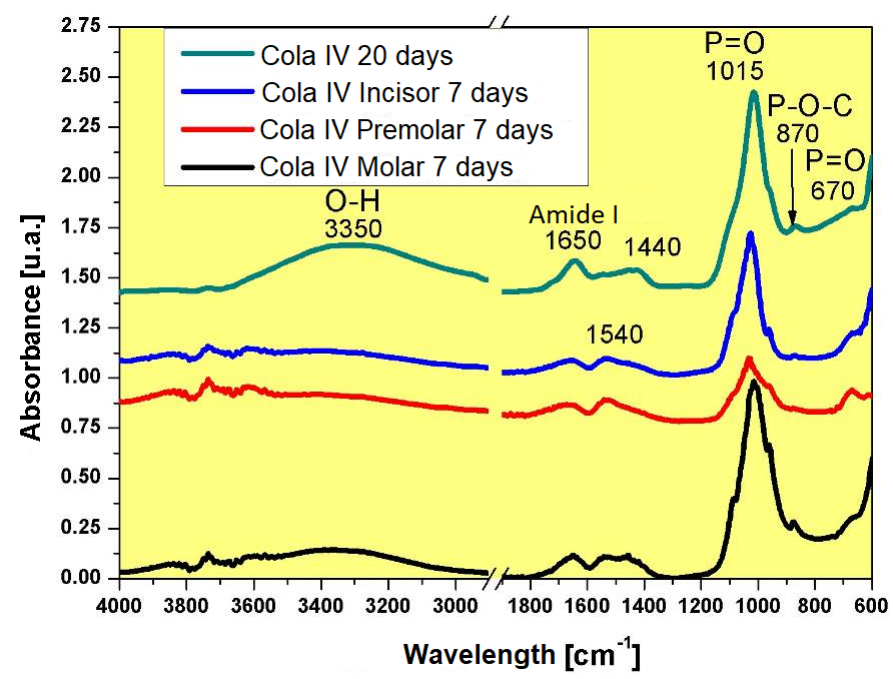

Figure 4-b. The absorption spectra ATR-FTIR of the human teeth demineralized with Coca Cola solution and remineralized with the experimental gel G29. 
UV-Vis recordings were made in the $400-900 \mathrm{~nm}$ range, on human enamel samples, before / after demineralization and after remineralization. The spectra were used to determine mineral loss and gain during demineralization remineralization process. (Fig. 5, 6).

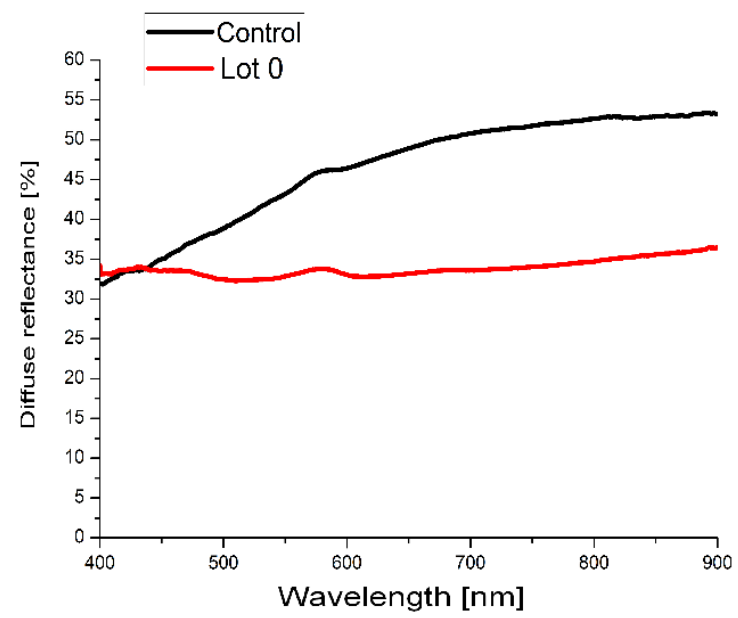

Figure 5. UV-VIS reflexion spectra for control group (enamel untreated) and Lot 0 (enamel demineralized)

In figure 5 is showed a decrease of diffuse reflectance after tooth demineralization (group 0), compared with the control of the sample.
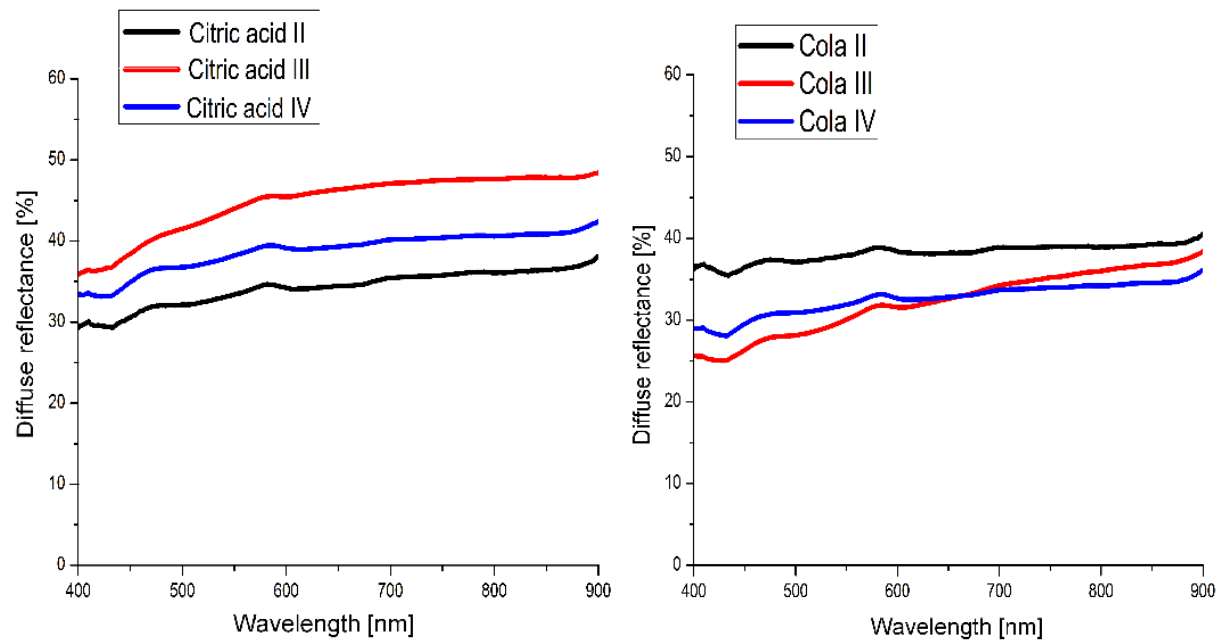

Figure 6. UV-VIS reflexion spectra for teeth demineralized in citric acid and Cola, remineralized with GC Tooth Mousse@ (II), Remin Pro@ (III) and experimental gel (IV) 
Figures 6 show the diffused reflectance of the teeth from group 0 , after the remineralization with commercial toothpaste, respectively the experimental gel. The decrease of the reflectance during the demineralization and its increase after the remineralization is the result of continuous changes of the crystals on the enamel surface during these processes.

According to the specialized literature, based on the optical diffusion properties, the demineralization processes of the teeth can be analyzed quantitatively and qualitatively, the color parameters and the translucency can be determined. The possible advantages of using optical methods of analysis in the field of dental medicine are related to the simplicity of the method of analysis in view of the fact that it is a non-destructive method, which involves relatively low costs, and the analysis can be performed without the need for direct contact with the dental tissue. Based on these optical analyzes, the demineralization processes of the teeth can be detected in early stages

The demineralization process can be discontinuing by providing a suitable environment for remineralization by means of different remineralizing agents. If demineralization exceeds the self-regulated remineralization, excessive loss of mineral content may take place, endangering the integrity of the tooth $[8,9]$.

The early stages of demineralisation involve a softening of the enamel surface to a depth of the order of 1-10 microns. Many studies were developed to understand the process of enamel demineralization at the very beginning, in order to appreciate if these early stages are reversible [10]. Saliva provides protective effects by neutralizing and cleaning the acids; it is a source of inorganic ions necessary for the remineralization process. Enamel has no spontaneous capability to repair when affected by specific dental pathologies such as caries, abrasions or fractures because it contains no cells [11, 12].

The results of previous studies have suggested that an IR peak near $1015 \mathrm{~cm}^{-1}$ is indicative of acid-induced alteration of the atomic bonding in superficial enamel apatite $[13,14,15]$.

The mineral in dental enamel is a calcium-deficient carbonated HAp containing fluoride. A simplified formula for tooth mineral composition is Ca10 $-x \operatorname{Nax}(\mathrm{PO} 4) 6-\mathrm{y}(\mathrm{CO} 3) \mathrm{z}(\mathrm{OH}) 2-\mathrm{u} F u ; 27$ thus, enamel differs from 'stoichiometric' HAp, which has the formula (Ca10(PO4)6(OH)2) [12,14]. The ATR-FTIR spectrum of the enamel surface (Figure 1a) was consistent with the results obtained in previous studies. A very strong peak was observed at $\sim 1015$ $\mathrm{cm}^{-1}$, which was attributed to the phosphate (PO4) anti-symmetric stretching mode (v3). The phosphate symmetric stretching mode (v1 PO4) appeared at $962 \mathrm{~cm}^{-1}$. Strong peaks assigned to B-type carbonate substitution (carbonate substitution for the phosphate ion) were observed at $872 \mathrm{~cm}^{-1}$ (v2 CO3) and at 
1405 and $1450 \mathrm{~cm}^{-1}$, respectively (v3 CO3).29 Substitutions (especially by carbonate) in the mineral crystal lattice weaken enamel structure, rendering the mineral more acid-soluble than $\operatorname{HAp}[16,17,18]$.

In Figure 1, ATR-FTIR spectra for the teeth in control group, all representative spectra recorded in the region of $800-1180 \mathrm{~cm}^{-1}$ presented the specific hydroxyapatite bands, respectively the vibration bands $P=0$ assigned to the phosphate $\left(\mathrm{PO}_{4}{ }^{3-}\right)$ at $1100-1000 \mathrm{~cm}^{-1}$, accompanied by a secondary vibration band at $870 \mathrm{~cm}^{-1}$ specific also for P-O-C of hydroxyapatites. Maximum absorption rates at $1650 \mathrm{~cm}^{-1}, 1540 \mathrm{~cm}^{-1}$ and $1450 \mathrm{~cm}^{-1}$ can be assigned to amide I and amide II bands from the proteins found the enamel structure, with $\mathrm{C}=\mathrm{O}$ and $\mathrm{N}-\mathrm{H}$ vibrations. In addition, another large absorption band detected at $3700-3000 \mathrm{~cm}^{-1}$ was assigned to hydroxyl group $(\mathrm{O}-\mathrm{H})$ with a secondary band at $1640 \mathrm{~cm}^{-1}$, which may overlap over amine I bands $[19,20]$.

For the specimens in control group, analysed at 7 and 20 days, we did no notice modification regarding dental structure, in accordance with the data found in literature $[13,16]$.

When compared the specimens spectra from study group 1 (teeth remineralized with GC Tooth Mousse $\odot$ ), with the specimens in control group, we notice at 7 and 20 days, increased values for hydroxyl bands at $3350 \mathrm{~cm}^{-1}$ and $1630 \mathrm{~cm}^{-1}$ while for the amide I bands from $1440 \mathrm{~cm}^{-1}$ the absorption has the tendency to decrease. A possible explanation of the phenomena resides in water content of hydroxyapatite.

The casein phosphopeptide-amorphous calcium phosphate technology developed based on the alleviating properties of milk and salivary proteins. The casein phosphopeptides allow high concentrations of calcium, phosphate, and fluoride ions that stabilized in solution, in a bioavailable form for the promotion of remineralization [19, 21].

In our study, we noticed a displacement through wider vibration bands of the maximum absorption values, due to the interactions between calcium and phosphate (contained in enamel and the remineralization paste).

No significant statistic difference emerged between specimens in first study group, unconcerned demineralizing solutions and the specimens in control group.

For the second study group, the demineralization protocol respect the algorithm presented for study group 1 , but for remineralization we used Remin Pro@, a commercial paste having hydroxyapatites and sodium fluoride in composition.

When compared demineralization (with citric acid solution) spectra and remineralization (with Remin Pro@) spectra, phosphate bands were detected increased for the study group specimens. This aspect is in accordance with 
data found in the literature, because it indicates an increasing degree of mineralization of the hydroxyapatites groups from enamel structure. No significant statistic difference between specimens in second study group and the specimens in control group was notice [10, 22].

For the third study group, teeth were de-mineralized applying the same protocol as for the first two study groups, but in the remineralization process we used an experimental gel made by the Institute of Chemistry "Raluca Ripan" Cluj Napoca. The vibration observed was characteristic for hydroxyapatites and amelogenin proteins from the enamel, but with no significant statistical difference compared with the specimens from the control group.

The basic principle of remineralization is by advocating a biological or non-invasive approach rather than the surgical approach for early enamel lesions. The demineralization - remineralization cycles occur throughout the lifetime, which attributes to the limited reparability of the enamel by mineral gain [23].

As the study is limited to in vitro conditions, further clinical trials are required to assess the remineralization potential of various products. The influence of saliva and plaque/pellicle on enamel was not addressed in this study [24]. In addition, dental plaque/pellicle may provide a significant level of enamel protection against demineralization generated by acidic beverages.

\section{CONCLUSIONS}

Under the limitations of the present in vitro study, the application of the tested product proved to be effective on initiated/ preventing enamel demineralization. Enamel softened by acidic beverages can re-harden following exposure to selected products by simple application of tested gels.

\section{EXPERIMENTAL SECTION}

40 caries free extracted human teeth, obtained under a protocol approved by the University's Ethics Committee (decision nr.221/17.05.2017), were divided into 4 groups. Study groups included teeth from anterior and lateral sector of dental arch, extracted for orthodontic or periodontal purposes.

Exclusion criteria for teeth were as follows:

- Teeth with cracks or discoloration;

- Teeth with enamel hypoplasia or any other developmental anomalies;

- Teeth procured from a patient suffering from transmissible or systemic conditions affecting hard tissues. 
After the extraction, teeth were cleansed of soft tissue and debris inspected for cracks, hypoplasia and white spot lesions; they were disinfected in $5.25 \%$ sodium hypochlorite solution for one hour and stored in artificial saliva until used.

Teeth were randomly divided into 3 study groups $(n=12)$, and 1 control group $(n=4)$. Teeth from each study group were prepared for the demineralization - remineralization process. For demineralization, teeth were immersed in $10 \mathrm{ml} 0.1 \%$ citric acid solution $(n=6)$ and in Coca-Cola solution $(n=6)$. Demineralization procedure: 20 minutes in demineralizing solution, 3 times a day, for 20 days.

After demineralizing, a remineralization product was applied on every tooth. Between demineralization/remineralization procedures, teeth were kept in artificial saliva (AS) at $37^{\circ} \mathrm{C}$ until next day.

For the study groups (3), the remineralization agent differed, as follows:

Group II - a commercial remineralization tooth-paste GC Tooth Mousse $\odot$ (Recaldent);

Group III - Remin Pro@ (Voco),

Group IV - an experimental gel (G29) made by the "Raluca Ripan" Chemistry Institute, Cluj Napoca, Romania, based on natural ingredients. The experimental gel G29 contains: coloidal silica/ hydroxyapatite/ hydroxyapatite with zinc oxide $=1: 2: 3$, lyophilized concentrate from pineapple and quince, vegetal pectin $=4-6 \mathrm{~g}, \mathrm{pH}=7.5-8$.

The remineralizing products were applied neat onto the surface of the teeth, without brushing, for $3 \mathrm{~min}$, and then washed with distilled water and store in artificial saliva (AS).

Teeth from control group were immersed in $A S$ at $37^{\circ} \mathrm{C}$ for 20 days. AS, with a pH of 7.4 , contained $1.5 \mathrm{mmol} / / \mathrm{CaCl}_{2}, 50 \mathrm{mmol} / \mathrm{KCl}$, and 20 $\mathrm{mmol} / \mathrm{l}$ Tris - tris(hydroxymethyl)aminomethane.

\section{ATR-FTIR spectroscopy}

In the present in vitro study, ATR-FTIR (Attenuated Total Reflection Fourier Transform Infrared Spectroscopy) (Jasco-610, Japan) was used to verify the protective effect of the remineralizing products on enamel exposed to the deminelazing solutions. The specimens were analysed at 7 days and 20 days of demineralization-remineralization process.

All the representative spectra recorded in the region of $800-1800 \mathrm{~cm}^{-1}$ (at $4 \mathrm{~cm}$ ) showed phosphate bands representative of mineral components. The phosphate bands increased during the seven-day period in the BG group. Increased phosphate peaks were also observed in the BG group after 14 and 21 days. 
L. SILAGHI-DUMITRESCU, A. MUNTEAN, A.M. MIHĂILESCU, C. SAROSI, D. PRODAN, M.R. SIMU, M. MOLDOVAN, A. KUI, M. PASTRAV

\section{UV-Vis spectroscopy}

Spectra were collected in the range of $400-900 \mathrm{~nm}$, using UV-Vis Lambda 35 spectrometer, equipment with integrated sphere and $0 \%$ geometric configuration, was measured diffuse reflectance. Each specimen was analysed in 3 different positions before and after treatment.

\section{REFERENCES}

1. L. Chen, K. Liang, J. Li, D. Wu, X. Zhou, J. Li, Arch Oral Biol, 2013, 58, 975-980.

2. T. Leventouri, A. Antonakos, A. Kyriacou, Int J Biomater, 2009, 2009, 698547.

3. Z. Wang, T. Jiang, S. Sauro, Y. Wang, I. Thompson, T.F. Watson, Y. Sa, W. Xing, Y. Shen, M. Haapasalo, J Dent, 2011, 39,746-756.

4. L. Gu, J. Kim, Y.K. Kim, Y. Liu, S.H. Dickens, D.H. Pashley, L. Jun-qi, R.T. Franklin, Dent. Mater., 2010, 26, 1077-1089.

5. I.C. Fort, G. Turdean, R. Barabas, D. Popa, A. Ispas, M. Constantiniuc, Stud UBB Chem, 2019, 1, 125-133.

6. D. Skrtic, J.M. Antonucci, E.D. Eanes, J Res Natl Inst Stand Technol, 2003, 108, 167-182.

7. M.G. Gandolfi, P. Taddei, F. Siboni, E. Modena, E. Dorigo De Stefano, C. Prati, Dent Mater, 2011, 27, 1055-1069.

8. T. Narongdej, R. Sakoolnamarka, T. Boonroung, J Am Dent Assoc, 2010, 141, 995-999.

9. A.P. Forsback, S. Areva, J.I. Salonen, Acta Odontol Scand, 2004, 62, 14-20.

10. Y. Fan, J.R. Nelson, J.R. Alvarez, J. Hagan, A. Berrier, X. Xu, Acta Biomater, 2011, 7, 2293-2302.

11. A. Lussi, E. Hellwig, D. Zero, T. Jaeggi, Am J Dent, 2006, 19, 319-325.

12. M. Oshiro, K. Yamaguchi, T. Takamizawa, H. Inage, T. Watanabe, A. Irokawa, S. Andro, M. Miyazaki, J Oral Sci, 2007, 49, 115-120.

13. X. Wang, A. Klocke, B. Mihailova, L. Tosheva, U. Bismayer, J. Phys. Chem. B, 2008, 112, 8840.

14. X. Hu, Y. Peng, C.P. Sum, J. Ling, J Endod, 2010, 36, 2008-2011.

15. X. Wang, B. Mihailova, A. Klocke, U. E. Fittschen, S. Heidrich, M. Hill, R. Stosch, B. Guttler, J.A. Broekaert, U. Bismayer, J Biomed Mater Res A, 2009, 88, 195-204.

16. H. Eimar, E. Ghadimi, B. Marelli, H. Vali, S.N. Nazhat, W.M. Amin, J. Torres, O. Ciobanu, R.F. Albuquerque Junior, F. Tamimi, Acta Biomater, 2012, 8, 34003410.

17. J. Reyes-Gasga, E.L. Martínez-Piñeiro, G. Rodríguez-Álvarez, G.E. TiznadoOrozco, R. Garcia-Garcia, E.F. Bre, Mater Sci Eng C, 2013, 33, 4568-4574.

18. C. Xu, R. Reed, J.P. Gorski, Y. Wang, M.P. Walker, J Mater Sci, 2012, 47, 80358043. 
19. M. Selimovic-Dragas, L. Hasic-Brankovic, F. Korac, N. Đapo, A. Huseinbegovic, S. Kobaslija, M. Lekic, S. Hatibovic-Kofman, Bosn J Basic Med Sci, 2013, 13, 197-202.

20. D. Sucala, C. Sarosi, Catalin Popa, I. Cojocaru, M. Moldovan, G.A. Mohan, Stud UBB Chem, 2018, 2, 71-81.

21. G.M. Hassan, E. Aboelezz, A. El-Khodary, H.M. Eissa, Nucl Instrum Methods Phys Res, 2010, 268, 2329-2336.

22. J.A. Cury, L.M.A. Tenuta, Braz Oral Res, 2009, 23, 23-30.

23. B. Culic, C. Gasparik, M. Varvara, C. Culic, C. Dragos, L. Silaghi-Dumitrescu, D. Dudea, Stud UBB Chem, 2017, 1, 61-71.

24. S.S. Narayana, V.K. Deepa, S. Ahamed, E.S. Sathish, R. Meyappan, K.S. Satheesh Kumar, J Indian Soc Pedod Prev Dent, 2014, 32, 19-25. 